\title{
LA BIBLIOTECA CONJETURAL DE NORA PASTERNAC Gabriel Astey*
}

\section{NORA PASTERNAC'S CONJECTURE LIBRARY}

RESUMEN: Utilizando como motivo conductor la idea de que la biblioteca de un académico refleja su ethos y su cosmovisión, este texto epidíctico celebra la trayectoria intelectual de Nora Pasternac, profesora del Departamento Académico de Lenguas del ITAM.

PALABRAS ClaVE: Jorge Luis Borges, Witold Gombrowicz, Vladimir Nabokov, Bruno Schulz.
ABSTRACT: Using as a driving motif the idea that an academic's library reflects his ethos and wordview, this epidictic text celebrates the intellectual trajectory of Nora Pasternac, professor of the Academic Department of Languages at ITAM.

KEYWORDS: Jorge Luis Borges, Witold Gombrowicz, Vladimir Nabokov, Bruno Schulz. 


\section{LA BIBLIOTECA CONJETURAL DE NORA PASTERNAC*}

uien, sin conocer a Nora Rosenfeld de Pasternac ni su producción intelectual, leyera el expediente - cuya publicación en la revista Estudios $^{1}$ nos reúne hoy aquí- con los textos que le hemos dedicado sus colegas del Departamento Académico de Lenguas, se podría enterar con bastante detalle de la trayectoria profesional de una notable mujer de letras, pero creo que, sobre todo, no podría evitar darse cuenta de que Nora es una persona interesantísima: transterrada y cosmo-

* Texto leído en el marco del "Homenaje a la Dra. Nora Pasternac" el miércoles 27 de marzo de 2019 en la Sala de Maestros del ITAM, campus Río Hondo.

${ }^{1}$ Carlos Gutiérrez Lozano, Rosa Margarita Galán Vélez, Carlos J. McCadden Martínez et al., "Dossier. Homenaje a Nora Pasternac", Estudios, núm. 127 (2018), pp. 43-98. polita, feminista, profesora de lenguas y literaturas, historiadora de las instituciones literarias, arqueóloga de la narrativa y el periodismo escritos por mexicanas, crítica, traductora, lacaniana "morganática" (como ella dice de sí misma), políglota, erudita, adamantina en sus muchas facetas.

Esa lectora o lector de nuestro dossier descubriría también en él la admiración y el cariño que sentimos por Nora sus compañeros de trabajo en el ITAM, y lo digo así porque se trata de un respeto y un afecto que trascienden los ámbitos departamental y divisional. Por lo que a mí respecta, debo decir que mi colaboración en el dossier fue una reseña de un libro sobre Simone de Beauvoir coeditado por la doctora Pasternac, de modo que ahora 
tengo la oportunidad de escribir para ella algo más personal y más cálido. La tarea es muy grata, pero nada fácil, porque mis colegas me han dejado el listón muy alto.

Con todo, quisiera imaginar aquí la biblioteca de Nora Pasternac; no describir su biblioteca empírica -que desconozco-, sino esbozar una biblioteca conjetural, un tejido de libros eidéticos, una literatura personalizada que sé que ella lleva en la memoria, el intelecto y el corazón, porque elípticamente me ha dejado leer - o me ha leído en voz alta - algunas de sus páginas en nuestras conversaciones. Hace unos días, pensando en esta charla y revolviendo mis libros, di con una sentencia enigmática de Vladimir Nabokov que me remitió al amor de Nora por los libros: "El espacio pone sus huevos en los nidos del tiempo". ${ }^{2}$ Si los libros son embriones en gestación, ¿dónde empolla sus libros un ave migratoria?, ¿cómo los cuida?, ¿en qué clase de equipaje los anida?, me pregunté. ¿Será verdad que las bibliotecas incuban libros y que los libros rompen el cascarón cuando los leemos? ¿O más bien la incubadora es la memoria y los libros nacen después de ser leídos, dentro de nosotros, al calor de otras experiencias que contribuyen a su eclosión?

${ }^{2}$ Vladimir Nabokov, Ada o el ardor, 2000, Barcelona, Anagrama, trad. de David Molinet, p. 443.
Sospecho que en la biblioteca física de la doctora Pasternac hay libros de su infancia y juventud argentinas, otros de su época francesa, y también muchos más de su vida en México, pero lo que sé a ciencia cierta es que en el tiempo personal de Nora, en su biblioteca íntima, hay una descomunal pajarera, con aves de muchas latitudes, diversas edades y distintos trinos, como anuncia ese pasaje de "La biblioteca total", de Borges, que ella cita en uno de sus estudios sobre la revista Sur:

Todo está en sus ciegos volúmenes. Todo: la historia minuciosa del porvenir, Los egipcios de Esquilo, el número preciso de veces que las aguas del Ganges han reflejado el vuelo de un halcón, el secreto y verdadero nombre de Roma, la enciclopedia que hubiera edificado Novalis, mis sueños y entresueños en el alba del catorce de agosto de 1934, la demostración del teorema de Pierre Fermat, [...] el cantar que cantaron las sirenas, el catálogo fiel de la Biblioteca, la demostración de la falacia de ese catálogo. ${ }^{3}$

Ahora bien, como la propia Nora escribe en ese estudio, la ficción de una biblioteca absoluta manifiesta "uno de los fundamentos de la literatura borgeana: que las cosas son y

${ }^{3}$ Jorge Luis Borges, "La biblioteca total", apud Nora Pasternac, "Borges en Sur", Estudios, 60-61 (2000), p. 57. 
al mismo tiempo no son, que llevan en su seno la posibilidad de la inexistencia, en un sistema que propone la ausencia de certidumbre sobre el mundo y la posibilidad de que no haya un sentido último". ${ }^{4}$ En efecto, y de vuelta a la metáfora-matriz de Nabokov, no todos los huevos del espacio se abren en el tiempo; las vidas humanas, unas más que otras, experimentan desgarraduras espaciales y cataclismos temporales, y del mismo modo que la biblioteca física no puede migrar completa junto con su dueña, seguramente la biblioteca íntima también tiene estantes con libros borrados o dañados, que no se quiere o no se logra releer. En suma, estas cosas no pueden suceder de otra manera: sin importar con cuanta dedicación aspiremos a leer entera la así llamada "literatura universal", lo único que conseguiremos (y no es poca cosa) será frecuentar una edición descabalada de la obras completas de la humanidad. Dicho esto, reitero con seguridad que el jardín interior de mi admirada colega rebosa de especímenes: la gran mayoría de las aves vive y canta dentro de ella; tiene lugar en su memoria, como en el clásico sufí, un coloquio de los pájaros.

En distinto pero vecino orden de asuntos, he de comunicar que Nora es también una avezada bibliotecaria

${ }^{4}$ Loc. cit. y bibliófila digital, que navega con soltura y pericia por internet y es capaz de encontrar ahí cuanta rareza y exquisitez erudita pueda uno imaginar, amén de que vale la pena recordar que la doctora Pasternac ha reflexionado y escrito sobre la literacidad digital y la disrupción tecnológica desde principios del siglo XXI; ${ }^{5}$ con todo, si hay algo que apesadumbra a Nora a propósito de la digitalización de los lazos sociales (y la acompaño en el pesar, como tantos otros) es la mediocridad lacunar y la prontitud a la disputa que aquejan a la conversación cultural contemporánea. La doctora Pasternac ha atestiguado suficientes guerras ideológicas como para arredrarse ante la más anémica y multipolar trifulca actual, pero aun así supongo que lamenta la cantidad de ruido presente en la biblioteca total digital.

En el orbe de la literatura rioplatense, puede respirarse avant la lettre la atmósfera erística que envuelve la discusión social on-line de nuestros tiempos en Transatlántico, la más argentina de las novelas de Witold Gombrowicz, en una de cuyas escenas el escritor polaco parodia la biblioteca total borgeana. El excéntrico millonario Gonzalo Andes recibe visitas en su lujosa estancia y los invitados descubren que todo, lite-

${ }^{5}$ Nora Pasternac, "Internet frente a la escritura", Estudios, 66 (2003), pp. 128-133. 
ralmente todo en esa casa se comporta como un perro, no solamente los perros zoológicos (que pululan, dicho sea de paso), sino también los muebles y los libros. El anfitrión, resignado, comenta:

—AAh, sí, la Biblioteca! —dijo Gonzalo-, la Biblioteca; pero, qué de problemas me da, qué de conflictos me produce. Contiene las Obras más preciosas, las más veneradas, escritas por los máximos genios, por los espíritus más selectos de la Humanidad, pero de qué me sirven, Señores, si se muerden, se muerden una a otra, y también debido a su número excesivo se devalúan, su excesiva abundancia las Abarata, porque hay Demasiadas, Demasiadas, y cada día llegan más y nadie puede leerlas porque son Demasiadas, ay, demasiadas. Entonces yo, señores, he debido contratar Lectores, y les pago un buen sueldo, porque me da vergüenza que todas esas obras se queden sin ser Leídas, pero son Demasiadas y estos hombres no pueden leer todo, aunque lean sin darse tregua el día entero. Lo peor es que los libros se Muerden como Perros, se muerden hasta darse Muerte. ${ }^{6}$

En épocas en que los libros se muerden como perros furiosos, conviene no olvidar, primeramente, que

${ }^{6}$ Witold Gombrowicz, Transatlántico, 1986, Barcelona, Anagrama, trad. de Kazimierz Piekarek y Sergio Pitol, p. 103. los libros desde hace algunos siglos son ya demasiados, de modo que se debe aprender a cultivar tan solo muchos de esos demasiados; en segundo lugar, también es oportuno recordar que los perros pueden amansarse y amistarse. La doctora Pasternac ha escrito con mucho tino sobre la profilaxis de los conflictos entre conceptos, discursos y doctrinas al reflexionar sobre el oficio de la traducción, un oficio que equivale a una artesanía de la concordia:

Traducir - dice Nora - no es solo traducir palabras, sino toda una cultura vehiculizada por esas palabras. Además, ante un texto accesible en la misma lengua en que fue escrito, la lectura abre la posibilidad, para el lector, de la ineludible intervención de su subjetividad, que funciona como una rejilla organizadora capaz de producir efectos de sentido variados. En cambio, en la traducción de un escrito en otra lengua, el traductor habrá de proponerse ofrecer a un presunto lector un texto que lo sitúe en la posibilidad de afrontar las "mismas" alternativas de sentido que el que lee el texto en la lengua original. $^{7}$

Me propuse bosquejar la biblioteca conjetural de mi admirada Nora. Veo que, más bien, he proyectado

${ }^{7}$ Nora Pasternac, "Reflexiones sobre la traducción y sus traiciones", Estudios, 37 (1994), p. 90. 
en ella mis conjeturas; apelando a su benevolencia, añado una última. ¿Qué nos impele a conservar un libro? Quizás el deseo de que nos acompañe un ser que amamos por único. Y a formar una biblioteca, ¿qué nos mueve? Rodearnos de tantos amados singulares como sea posible. Hablaba hace un momento con Gombrowicz de perros mordelones; transcribo en seguida, de la pluma de su amigo Bruno Schulz, el hallazgo de un cachorro precioso, el Nemrod del cuento homónimo:

Todo el mes de agosto de aquel año lo pasé jugando con un fabuloso perrito, que apareció un día en el suelo de nuestra cocina, torpe y chillón, aún oliendo a leche y a bebé, con una cabecita todavía no formada, redonda, ligeramente temblorosa, las patitas abiertas como las de un topo y el pelo suavísimo y delicado.

Desde el primer momento, esta gotita conquistó todo el encanto y todo el entusiasmo de mi alma infantil.
¿De qué cielo había descendido ese pupilo de los dioses, el más apreciado de todos los juguetes más bellos?

¡Qué bien que las viejas y vulgares lavanderas, totalmente desinteresadas, tengan a veces esas ideas y nos traigan del pueblo, a una hora temprana, trascendentalmente matutina, un perrito a nuestra cocina!

Estábamos, por desgracia, todavía ausentes, aún no habíamos nacido del regazo oscuro del sueño, cuando la felicidad se hizo realidad y nos esperaba, impedida, tumbada torpemente sobre el frío suelo de la cocina. ${ }^{8}$

Sé muy bien que los afectos de Nora son más felinos que perrunos, pero también sé que es amante de lo único, de modo que gracias a Schulz puedo imaginármela de niña, en un shtetl del Chaco, "a una hora temprana, trascendentalmente matutina", encontrando su primer gatito o su primer libro; inaugurando su biblioteca.
${ }^{8}$ Bruno Schulz, "Nemrod", en Madurar hacia la infancia. Relatos, inéditos y dibujos, 2008, Madrid, Siruela, trad. de Elzbieta Bortkiewickz y María Condor, p. 89. 